cally that changes in established practice would be opposed.

A major disadvantage of standardising glomerular filtration rate to surface area is that formulas for estimating surface area from weight or weight and length are based on relatively few actual measurements in the smallest weight range and have never been systematically tested in babies of varying body proportions. Practical neonatal management decisions, including those regarding calorie intake, temperature control, and fluid, electrolyte, and drug administration are almost universally made on the basis of body weight, which can be measured directly. Even workers who standardise their glomerular filtration rate results $/ \mathrm{m}^{2}$ generally calculate the doses of their test substances per $\mathrm{kg}$ body weight. For research findings to be usefully assimilated and applied clinically, they should be expressed in the same way as other parameters.

It has been argued that it would be logical to relate glomerular filtration rate to the size of the fluid pool affected by the kidney ${ }^{5}{ }^{6}$ but this has three disadvantages. Firstly, like surface area, fluid volumes would be estimated rather than measured. Secondly, no single fluid space would be appropriate to all aspects of renal function; total body water would be best for urea and water handling, ${ }^{5}$ and extracellular fluid volume for inulin or mannitol clearances. ${ }^{6}$ Thirdly, like surface area:weight, the total body water:weight and extracellular fluid volume:weight ratios fall with increasing postconceptual age, exaggerating the rises in glomerular filtration rate with increasing body size.

We have shown that weight, the only reference standard that can be actually measured and is clinically useful, is the best index for neonatal glomerular filtration rate measurement. To expect a single standard to apply to all patients weighing from 1 to $70 \mathrm{~kg}$ is simplistic, however, and could be misleading. It is better to consider glomerular filtration $\mathrm{rate} / \mathrm{kg}$ as useful in the newborn period and glomerular filtration $\mathrm{rate} / \mathrm{m}^{2}$ as convenient in older children, and not to place physiological importance on either approach.

We thank Mrs Valerie Ruddock for skilled technical assistance and Mrs Marjorie Renwick for secretarial help. This work was supported by Medical Research Council project grant 9979279 .

\section{References}

1 Coulthard MG. Comparison of methods of measuring renal function in pre-term babies using inulin. $J$ Pediatr 1983;102: 923-30.

2 Boyd E. The growth of the surface area of the human body. Minneapolis: University of Minnesota Press, 1935.

${ }^{3}$ Hey EN. The relation between environmental temperature and oxygen consumption in the new-born baby. $J$ Physiol 1969;200:589-603.

${ }^{4}$ Tanner JM. Fallacy of per-weight and per-surface area standards, and their relation to spurious correlation. J Appl Physiol 1949:2:1-15.

5 McCance RA, Widdowson EM. The correct physiological basis on which to compare infant and adult renal function. Lancet 1952;ii:860-2.

' Newman EV, Bordley J, III, Winternitz J. The interrelationships of glomerular filtration rate (Mannitol clearance), extracellular fluid volume, surface area of the body, and plasma concentration of mannitol: definition of extracellular fluid clearance determined by following plasma concentration after single injection of mannitol. Bulletin of the Johns Hopkins Hospital 1944:75:253-68.

7 Haycock GB. Schwartz GJ. Wisotsky DH. Geometric method for measuring body surface area: a height-weight formula validated in infants. children, and adults. $J$ Pediatr 1978:93:62-6

Correspondence to Dr M G Coulthard. Guys Hospital, St Thomas Street, London SE1 9RT.

Received 20 November 1983

\title{
Cushing's syndrome and bronchial carcinoid tumour
}

\author{
P S WARD, M G MOTT, J SMITH, AND M HARTOG \\ Bristol Royal Hospital for Sick Children and Southmead Hospital, Bristol
}

\begin{abstract}
SUMmary Adrenal function test results in a girl with Cushing's syndrome and a bronchial carcinoid tumour suggested pituitary dependent hypercortisolism. Resolution after excision of the tumour indicated that her condition had been caused by ectopic adrenocorticotrophic hormone secretion. Conventional tests of adrenal function may be misleading in cases of adrenocorticotrophic hormone secreting bronchial carcinoid tumours.
\end{abstract}

The aetiology of Cushing's syndrome can usually be determined from the serum adrenocorticotrophic hormone concentration and the response of urinary corticosteroids to high dose dexamethasone and metyrapone. ' In some circumstances, however, these investigations may be misleading. ${ }^{2}$ We report a patient who seemed to have pituitary dependent hypercortisolism but was subsequently shown to have an adrenocorticotrophic hormone secreting bronchial carcinoid tumour. 


\section{Case report}

A 15 year old girl presented with a 14 month history of weight gain, hirsutism, acne, and striae and an 8 month history of secondary amenorrhoea after menarche at the age of 14 years. Her height was 160 $\mathrm{cm}$, weight $63.8 \mathrm{~kg}$ and pubertal stage $\mathrm{P}_{5} \mathrm{G}_{5}$. Examination showed central obesity, 'moon face', cervicothoracic fat pad, acne, hirsutism, and purple striae of breasts, thighs and abdomen. Her blood pressure was $130 / 85 \mathrm{mmHg}$.

A skull radiograph, tomography of the pituitary fossa, intravenous urogram, and computed tomography of the abdomen were normal. A chest radiograph showed a rounded lesion in the right lung. The urinary 5 hydroxyindoleacetic acid (5HIAA) concentration was raised at $15.9 \mathrm{mmol} /$ mol creatinine (normal $0-4 \mathrm{mmol} / \mathrm{mol}$ creatinine).

Results of adrenal function tests are shown in the Table. Values of plasma cortisol and urinary cortisol derivatives (mainly cortisol itself and tetrahydrocortisol) were raised. Plasma adrenocorticotrophic hormone concentrations were moderately raised. Urinary cortisol derivative excretion was suppressed with high dose dexamethasone $(8$ $\mathrm{mg}$ daily) but not low dose dexamethasone $(2 \mathrm{mg}$ daily). Urinary cortisol precursors (mainly 11deoxycortisol, Compound S) and derivatives increased after she was given metyrapone $(750 \mathrm{mg}$ four hourly for 6 doses).

The tumour was excised and the postoperative period was uneventful. Six months later her weight had fallen to $48.6 \mathrm{~kg}$ and the stigmata of Cushing's syndrome, other than the striae, had disappeared. Plasma cortisol values and urinary corticosteroid excretion returned to normal.

\section{Pathological studies}

Conventional light microscopy showed the tumour to be a bronchial carcinoid. Histochemical investigations showed positive argyrophil and argentaffin staining of cytoplasmic granules. Round dense cytoplasmic neurosecretory granules were shown by electron microscopy. Immunohistochemical staining was positive for adrenocorticotrophic hormone and tumour tissue tested against a panel of monoclonal antibodies (Frenchay Hospital, Bristol) was positive to neuroectodermal markers UJ13A and H11.

Tumour extract contained immunoreactive ' $N$ ' terminal adrenocorticotrophic hormone, immunoreactive ' $C$ ' terminal adrenocorticotrophic hormone, immunoreactive $\beta$ endorphin, and immunoreactive $\gamma$ melanocyte stimulating hormone. Chromatography of adrenocorticotrophic hormone obtained from tumour tissue showed only a single band corresponding to 1-37 adrenocorticotrophic hormone. Plasma contained immunoreactive $\gamma$ melanocyte stimulating hormone and immunoreactive $\beta$ endorphin. (St Bartholomew's Hospital, London).

\section{Discussion}

Pituitary dependent hypercortisolism is usually associated with serum adrenocorticotrophic hormone concentrations of less than $200 \mathrm{ng} / \mathrm{l}$, suppression of urinary cortisol derivatives with high dose dexamethasone, and increased urinary cortisol precursors and derivatives with metyrapone. ${ }^{1}$ Typically, in the ectopic adrenocorticotrophic hormone syndrome, serum adrenocorticotrophic hormone concentrations exceed $200 \mathrm{ng} / \mathrm{l}$ and urinary corti-

Table Adrenal function tests

\begin{tabular}{|c|c|c|c|c|c|c|}
\hline Day & Treatment & $\begin{array}{l}\text { Urinary } \\
\text { cortisol } \\
\text { derivatives* } \\
\text { (mmol/mol creatinine) }\end{array}$ & $\begin{array}{l}\text { Urinary } \\
\text { cortisol } \\
\text { precursorst } \\
\text { (mmol/mol creatinine) }\end{array}$ & Time & $\begin{array}{l}\text { Serum } \\
\text { adrenocorticotrophic } \\
\text { hormone }^{\ddagger} \\
\text { (ng/l) }\end{array}$ & $\begin{array}{l}\text { Plasma } \\
\text { cortisol\$ } \\
\text { (mmol/l) }\end{array}$ \\
\hline 1 & Basal & $13 \cdot 4$ & 0.5 & 1100 & $\overline{170}$ & 625 \\
\hline 2 & Basal & $13 \cdot 1$ & $1 \cdot 3$ & $\begin{array}{l}0900 \\
2400\end{array}$ & 110 & $\begin{array}{l}760 \\
615\end{array}$ \\
\hline 3 & Dexamethasone $(0.5 \mathrm{mg} 6$ hourly $)$ & - & - & $090(0)$ & 160 & 502 \\
\hline 4 & Dexamethasone $(0.5 \mathrm{mg}$ hourly) & $14 \cdot 7$ & 0.5 & & & \\
\hline 5 & Dexamethasone ( $2 \mathrm{mg} 6$ hourly). & $13 \cdot 3$ & 0.9 & & & \\
\hline 6 & Dexamethasone ( $2 \mathrm{mg} 6$ hourly) & $6 \cdot 5$ & 0.4 & & & \\
\hline 12 & Basal & $15 \cdot 7$ & $0 \cdot 4$ & & & \\
\hline 13 & Metyrapone $(750 \mathrm{mg} 4$ hourly) & $28 \cdot 0$ & $17 \cdot 7$ & & & \\
\hline 14 & Basal & $77 \cdot 0$ & $4 \cdot 3$ & & & \\
\hline
\end{tabular}

${ }^{*}$ Normal, $1 \cdot 0-3.8 \mathrm{mmol} / \mathrm{mol}$ creatinine.

†Normal $0.2-(1) \cdot 6 \mathrm{mmol} / \mathrm{mol}$ creatinine

$\ddagger$ Normal. $<80 \mathrm{ng}^{\prime} \mathrm{l}$ at $9 .(00) \mathrm{am}$

$\$$ Normal, $130-600 \mathrm{mmol} / \mathrm{l}$ at $9 .(00 \mathrm{am}$ 
costeroids are unaffected by high dose dexamethasone and metyrapone.

In our patient, the adrenal function tests were so consistent with pituitary disease that the pulmonary lesion was initially thought to be coincidental. However, the resolution of hypercortisolism after excision of a tumour, known in adults ${ }^{3}$ to be associated with the ectopic adrenocorticotrophic hormone syndrome, and the finding of adrenocorticotrophic hormone and related peptides in the tumour, confirmed the diagnosis of ectopic adrenocorticotrophic hormone secretion.

Serum adrenocorticotrophic hormone concentrations in pituitary dependent and ectopic adrenocorticotrophic hormone dependent hypercortisolism overlap, and dexamethasone responsive bronchial carcinoids have been reported in adults. ${ }^{2}$ Metyrapone in the dosage used produces a varying degree of block in patients with Cushing's syndrome. The block was incomplete in our patient. The very high values of cortisol derivatives found after the drug was given would usually be explained by the exaggerated pituitary adrenocorticotrophic hormone and cortisol response in patients with pituitary dependent disease resulting from a fall in circulating cortisol values in the first few hours of metyrapone administration.

Bronchial carcinoid tumours are rare in children, ${ }^{4}$ but as they may recur and metastasise a reliable tumour marker would be valuable. Although in this patient the pattern of adrenocorticotrophic hormone related peptides in plasma did not indicate the source of secretion, recent studies of adrenocorticotrophic hormone and related peptides in plasma and tumour tissue suggest that this may eventually permit more accurate aetiological diagnosis of Cushing's syndrome and act as a tumour marker. ${ }^{5}$

We thank Dr Betty Brownell and Mr H Coakham, Frenchay Hospital, Bristol and Professor Lesley Rees, St Bartholomew's Hospital, London, for the special investigations. PSW and MGM are supported by the Cancer and Leukaemia in Childhood Trust.

\section{References}

' Liddle GW. Cushing's syndrome. Ann NY Acad Sci 1977;297:594-601.

2 Gold EM. The Cushing's syndrome: changing views of diagnosis and treatment. Ann Intern Med 1979;90:829-44.

3 Azzopardi JG, Williams ED. Pathology of 'non-endocrine' tumours associated with Cushing's syndrome. Cancer 1968;22:274-86.

4 Lack EE, Harris GBC, Eraklis AJ, Vawter GF. Primary bronchial tumours in childhood. A clinicopathological study of six cases. Cancer 1983;51:492-7.

5 Ratter SJ, Gillies G, Hope J, et al. Pro-opiocortin related peptides in human pituitary and ectopic ACTH secreting tumours. Clin Endocrinol (Oxf) 1983;18:211-8.

Correspondence to Dr P S Ward, Bristol Royal Hospital for Sick Children, Bristol.

Received 28 December 1983

\title{
Arthritis in cystic fibrosis
}

\author{
D V SCHIDLOW, D P GOLDSMITH, J PALMER, AND N N HUANG
}

\begin{abstract}
Sections of Pulmonary Disease and Rheumatology, St Christopher's Hospital for Children, Philadelphia, USA
\end{abstract}

SUMMARY We have confirmed previous observations of a transient, non-disabling recurrent arthritis in patients with cystic fibrosis. This arthritis differs from classic rheumatoid arthritis, is frequently associated with skin arthritis lesions, and its occurrence is unrelated to the severity of lung disease.

The association of a transient arthritis with cystic fibrosis was first reported by Newman and Ansell in 1979. ${ }^{1}$ We describe the clinical course and laboratory findings in 8 cystic fibrosis patients with acute arthritis not associated with pulmonary osteoarthropathy.

\section{Patients}

The group comprised 6 girls and two boys aged 3 to 29 years (mean 13.5 years). The diagnosis of cystic fibrosis had been made on the basis of clinical and radiological findings, and raised sweat electrolyte measurements. At the onset of joint disease, pulmonary disease was mild in five patients, moderate in two, and advanced in one. Six patients were taking pancreatic enzyme preparations; five had Pseudomonas aeruginosa in their sputum cultures; and 6 were taking oral antibiotics continuously, two on a sporadic basis. Clubbing of varying severity was present in all patients, however, none had long bone pain or radiological evidence of periosteal elevation. 